\title{
The effect of meloxicam on behavior and pain sensitivity of dairy calves following cautery dehorning with a local anesthetic
}

\author{
A. Heinrich, ${ }^{*}$ T. F. Duffield,${ }^{* 1}$ K. D. Lissemore, ${ }^{*}$ and S. T. Millman ${ }^{*} \dagger$ \\ *Department of Population Medicine, Ontario Veterinary College, University of Guelph, Guelph, ON, Canada, N1G 2W1 \\ †Veterinary Diagnostics and Animal Production Medicine/Biomedical Sciences, lowa State University, Ames 50011-1250
}

\begin{abstract}
Effects of a single injection of meloxicam on calf behavior, pain sensitivity, and feed and water intakes were examined following dehorning. Sixty Holstein heifer calves were blocked by age and randomly assigned to receive an i.m. injection of meloxicam (0.5 $\mathrm{mg} / \mathrm{kg}$ ) or a placebo. All calves were given a lidocaine cornual nerve block ( $5 \mathrm{~mL}$ per horn). Treatments and nerve blocks were administered 10 min before cautery dehorning. Continuous sampling of behavior was performed during five 1-h intervals using video recordings, and total daily activity was monitored using an accelerometer. A pain sensitivity test was administered with a pressure algometer, and feed and water intakes were recorded daily. Calves were sham-dehorned $24 \mathrm{~h}$ before actual dehorning to establish baseline values, and all variables were assessed at the same times following dehorning and sham dehorning for up to $48 \mathrm{~h}$ post-dehorning. Meloxicam-treated calves displayed less ear flicking during the $44 \mathrm{~h}$ following dehorning (increases of $4.29 \pm 1.10$ and $1.31 \pm 0.66$ ear flicks $/ \mathrm{h}$ in the first $24 \mathrm{~h}$, and increases of $3.27 \pm 0.89$ and $0.55 \pm$ 0.50 ear flicks/h during the second $24 \mathrm{~h}$, for control and meloxicam calves, respectively) and less head shaking during the first $9 \mathrm{~h}$ following dehorning (increase of $2.53 \pm 0.54$ and $0.85 \pm 0.46$ headshakes/h over baseline for control and meloxicam, respectively). Meloxicamtreated calves were less active than controls during the first $5 \mathrm{~h}$ following dehorning (activity $34.1 \pm 3.2$ and $30.6 \pm 2.6$ for control and meloxicam, respectively) and displayed less sensitivity to pressure algometry $4 \mathrm{~h}$ after dehorning (pressure tolerance of $1.62 \pm 0.13 \mathrm{~kg}$ of force and $2.13 \pm 0.15 \mathrm{~kg}$ of force for control and meloxicam calves, respectively). Changes in behavior suggest that meloxicam was effective for reducing post-surgical pain and distress associated with calf dehorning.
\end{abstract}

Key words: calf, dehorning, meloxicam, pain

Received October 9, 2009.

Accepted March 8, 2010.

${ }^{1}$ Corresponding author: tduffiel@ovc.uoguelph.ca

\section{INTRODUCTION}

Dehorning refers to amputation of horns in mature cattle or removal of the horn buds of calves; when conducted before 3 wk of age, it is referred to as disbudding. Dehorning is routine management practice on dairy farms, performed to prevent cattle from injuring each other as well as their human handlers. Even though dehorning is done with the long-term welfare of the animals in mind, it does cause acute pain or distress, as indicated by changes in plasma cortisol (Petrie et al., 1996; Sutherland et al., 2002; Heinrich et al., 2009), heart rate (Grøndahl-Nielsen et al., 1999; Stewart et al., 2008), eye temperature (Stewart et al., 2008), electroencephalogram (Gibson et al., 2007), and calf behavior (McMeekan et al., 1999; Sylvester et al., 2004). The degree of physiologic and behavior response varies with the method of dehorning. Amputation dehorning caused a greater cortisol response than dehorning by heat cauterization (Petrie et al., 1996).

Local anesthetics such as lidocaine and bupivacaine were effective for reducing physiologic and behavior responses to dehorning surgery (Graf and Senn, 1999). Yet, once the local anesthetic dissipated, cortisol (Sutherland et al., 2002) and behaviors such as ear flicking and head shaking increased, suggesting the presence of inflammatory pain for up to $24 \mathrm{~h}$ (Faulkner and Weary, 2000).

Researchers reliably described an increase in cortisol concentration immediately following dehorning without pain management associated with acute amputation pain (Stafford and Mellor, 2005). The absence of a cortisol response when dehorning was performed with cornual nerve blockade presented compelling evidence that the cortisol response was primarily pain related (Petrie et al., 1996; McMeekan et al., 1999; Sutherland et al., 2002).

Pain is a subjective state that can only be measured indirectly; Anil et al. (2002) suggest that behavior is a more sensitive indicator of pain than cortisol and other physiological measures. Differences in behavior were detected in the first $24 \mathrm{~h}$ after dehorning (Faulkner and Weary, 2000). Behavioral responses such as ear flicking, tail flicking, head shaking, head rubbing, rearing, and 
falling down were accepted as indicators of pain resulting from dehorning surgery (Faulkner and Weary, 2000; Stafford et al., 2003; Milligan et al., 2004).

Pressure algometry was used in cattle to objectively assess pain associated with integument lesions (Dyer et al., 2007; Liu et al., 2009). Mechanical threshold was measured in chronically lame cattle (Ley et al., 1996) using a device described in Nolan et al. (1987).

Nonsteroidal antiinflammatory drugs (NSAID) prevent inflammation by inhibiting cyclooxygenase (COX) enzymes, which produce prostaglandins. There are 2 primary isoforms of COX enzymes: COX-1 and COX2. Prostaglandins associated with the COX-1 isoform regulate processes such as maintenance of the gastrointestinal tract, renal function, and other homeostatic processes (Curry et al., 2005). Prostaglandins associated with the COX-2 isoform are associated with pain and inflammation that result from tissue injury. The NSAID ketoprofen effectively reduces inflammationrelated pain responses to dehorning (McMeekan et al., 1998; Faulkner and Weary, 2000) and is approved for use in cattle in several countries. However, ketoprofen has a short half-life in cattle, approximately 2 to 4 h (Landoni et al., 1995a), and cortisol data indicate that ketoprofen is not capable of eliminating the full duration of the pain response to dehorning (Sutherland et al., 2002; Stafford et al., 2003). Meloxicam is an NSAID with a half-life of approximately $26 \mathrm{~h}$ in cattle (European Agency for the Evaluation of Medicinal Products, 2006), and it preferentially inhibits the COX-2 isoform, whereas ketoprofen and flunixin meglumine (another NSAID approved for use in cattle with a half-life of approximately 6 to $7 \mathrm{~h}$; Landoni et al., 1995b) are nonspecific COX inhibitors (Papich, 2007). As a result, meloxicam may cause less interference with normal homeostatic processes and may have fewer deleterious effects on the gastrointestinal system, a factor particularly relevant to the developing rumen of the calf (Plumb, 2002). Meloxicam mitigated pain following dehorning with local anesthetic as measured by eye temperature, heart rate, and heart rate variability (Stewart et al., 2009) and cortisol, heart rate, and respiratory rate (Heinrich et al., 2009). The effects of meloxicam on pain-related behaviors associated with dehorning have not been examined.

The objectives were to determine the effects of meloxicam on pain-related behaviors, feed intake, water intake, and pain sensitivity.

\section{MATERIALS AND METHODS}

\section{Animals and Housing}

The study was conducted on 60 Holstein heifer calves, 6 to 12 wk (mean \pm SEM, $9 \pm 1$ wk) old, with a BW of $88.8 \pm 2.0 \mathrm{~kg}$ (range 55.5 to $129.0 \mathrm{~kg}$ ) at the Elora Dairy Research Centre of the University of Guelph (Guelph, Ontario, Canada) between September 2005 and July 2006. Sample size estimate was based on data from a previous study (Duffield et al., 2010).

Calves were used in a lighting trial until weaning at 6 wk of age, and a minimum of 2 calves of weaning age were needed for full replication on the current trial, necessitating use of calves up to 12 wk of age. Calves were housed in individual pens measuring $1.3 \times 1.5 \mathrm{~m}$ and were separated by partitions allowing visual and tactile contact with adjacent calves through vertical bars. The pens were located in an indoor nursery and the same 4 pens were used in all trials. Calf starter (20\% calf starter with lasalocid, Floradale Feed Mill, Elora, ON, Canada) was offered ad libitum from birth and became the sole feed following weaning. Weaning took place at 6 wk of age, before the calves were enrolled in the trial. The nursery was lit from 0545 until $2045 \mathrm{~h}$, and a single $100-\mathrm{W}$ bulb was hung in the middle of the nursery overnight. Temperature in the nursery was maintained at $8^{\circ} \mathrm{C}$ in the winter, but varied with outside temperature in the spring and summer (range 10 to $29^{\circ} \mathrm{C}$ ).

\section{Experimental Design and Treatments}

This experiment used a randomized complete block design with groups of 2 or 4 calves ( 1 or 2 complete replicates) over a total of 17 trials. Before each trial began, calves were blocked by age and randomly assigned to receive either meloxicam $(\mathrm{n}=30)$ or control $(\mathrm{n}=30)$ treatments. To control for environmental effects, calf pens were assigned to alternate treatments, and these treatments were reversed for each trial. To control for bias, all observers and staff were blind to the treatments.

For all calves, $5 \mathrm{~mL}$ of lidocaine $(2 \%$ lidocaine $\mathrm{HCl}$ with $0.05 \mathrm{mg} / \mathrm{mL}$ epinephrine, Bimeda-MTC, Cambridge, ON, Canada) was administered under the temporal ridge around each cornual nerve 10 min before dehorning. At this time, calves in the meloxicam treatment received a single i.m. injection of meloxicam (Metacam, $20 \mathrm{mg} / \mathrm{mL}$ solution for injection; Boehringer Ingelheim Vetmedica, Ingelheim am Rhein, Germany) in the neck at a dose of $0.5 \mathrm{mg} / \mathrm{kg}$ of BW. Control calves received a single i.m. injection of placebo solution with an equivalent volume as the treatment. The placebo solution was the Metacam vehicle with the active meloxicam ingredient removed and was identical in appearance to the Metacam solution. Calves were dehorned at $0930 \mathrm{~h}$ using an electric cautery iron (Rhinehart X30, Rhinehart Development Corp., Spencerville, IN). The iron was preheated for at least $10 \mathrm{~min}$ to a temperature of approximately $600^{\circ} \mathrm{C}$ before dehorning. Injections and 
dehorning were always performed by the same, trained technician.

To control for variation in pain responses between calves, a sham dehorning procedure was performed and baseline values collected for all measures. At $0930 \mathrm{~h}$ on the first day of the trial $(\mathrm{d}-1)$, calves were sham dehorned using an unheated dehorner. The responses of each calf to dehorning could then be compared with the response to sham dehorning and each calf acted as its own control. In addition, on $\mathrm{d}-1$, calves were fitted with jugular catheters at $0700 \mathrm{~h}$ to facilitate blood sampling for another component of the overall study that included cortisol measurement (Heinrich et al., 2009). All calves were bled via indwelling jugular catheters every $30 \mathrm{~min}$ from the time of dehorning and sham dehorning until $2 \mathrm{~h}$ following (Heinrich et al., 2009).

All procedures were approved by the Animal Care Committee of the University of Guelph Animal Utilization Protocol \#05R106.

\section{Data Collection}

Video cameras (Panasonic model WV BP100; http:// www.panasonic.com) equipped with wide-angle, color camera lenses (F 1.4/6 mm; Cosmicar, HS614GX, Pentax, Englewood, CO) were installed on the opposite wall to the calf pens, such that 1 camera provided a panoramic view of 2 pens. Calves were video recorded continuously from the time of sham dehorning $(\mathrm{d}-1)$ until $48 \mathrm{~h}$ following actual dehorning $(\mathrm{d} 0$ and +1$)$. All video was recorded using high quality Reco-204 DVR at 30 frames/s. Each calf was observed individually for five standardized 1-h periods following sham dehorning and ten 1-h periods following actual dehorning. These periods corresponded to approximately $-22,-20,-18$, $-15,-4,2,4,6,9,20,26,28,30,33$, and $44 \mathrm{~h}$ relative to dehorning. These times were chosen to correspond with significant events following dehorning (e.g., at $2 \mathrm{~h}$, when the local nerve block would be expected to have worn off; Petrie et al., 1996), in accordance with research on calf behavior (McMeekan et al., 1999; Faulkner and Weary, 2000) and with time periods associated with relatively high calf activity. Level of calf activity was determined using an accelerometer placed on the left hind leg of each calf (described below). Humans were not present in the nursery during observational periods, because the presence of a handler could alter the behavior.

Total activity was measured using biotelemetry accelerometer devices (Actical, Mini Mitter Respironics, Bend, OR) that recorded activity counts every $30 \mathrm{~s}$. Devices were placed on the left hind leg above the hock of each calf and bandaged in place approximately 2 $\mathrm{h}$ before sham dehorning and removed at $24 \mathrm{~h}$. Data were downloaded and stored as average activity counts per hour. One set of activity data was excluded from the analysis because the activity meter was removed overnight.

Behavior data were compiled using The Observer (Noldus Information Technology, Wageningen, the Netherlands). A complete ethogram is provided in Table 1. Frequency of events for each behavior was recorded within each 1-h period. Twelve of the 15 observational hours per trial were performed by one investigator $(\mathrm{AH})$. Three 1 -h periods $(-18,9$, and $30 \mathrm{~h})$ were analyzed by a second observer who was trained by $\mathrm{AH}$ and tested using periods of video that were watched by both observers simultaneously for agreement. Inter-observer reliability was assessed by comparing data compiled by each observer and sorted using Proc Sort and Proc Summary functions in SAS (version 9.1.3; SAS Institute Inc., Cary, NC). No differences in the frequency of behavior recorded by either observer were found. Both observers were blind to the NSAID treatment status of each calf (meloxicam vs. placebo).

Pain sensitivity was measured at $4 \mathrm{~h}$ following sham and actual dehorning using a pressure algometer (Force One FDI, Wagner Instruments, Greenwich, CT), and the same trained researcher performed all measurements. The device was equipped with a round rubber tip measuring $1 \mathrm{~cm}$ in diameter. The amount of pressure a calf tolerated was measured in kilograms of force ( $\mathrm{kgf})$ over the area of the rubber tip and was referred to as the mechanical nociceptive threshold (MNT). The calf was restrained with a halter and the researcher placed a hand lightly on the poll until the calf habituated to being touched and stood still in a relaxed posture. The hand was slowly removed and replaced with the algometer rubber tip placed directly beside the horn bud, such that the rubber tip covered the cautery wound and the edge of normal tissue. Pressure was applied perpendicular to the poll at a rate of approximately 1 $\mathrm{kgf} / \mathrm{s}$ until the calf withdrew its head. Four sites around each horn bud were measured in the same order for each horn (Figure 1). Half of the calves were tested on the left horn first, followed by the right horn during both sham and dehorning days; the other calves were tested on the right horn first. The algometer automatically read the highest level of pressure applied, and it was reset to zero after each application. To minimize bias, the researcher did not view the screen of the algometer until after the calf had withdrawn its head.

Following the 17 trials, 4 additional calves were subjected to identical methodology, except that a second sham dehorning was conducted on d 0 in place of cautery dehorning. This was done to test the validity of the algometer as a test for pain and not simply a frightening or otherwise unwanted stimulus. 
Table 1. Ethogram used for behavioral analysis from video recordings ${ }^{1}$

\begin{tabular}{ll}
\hline Behavior & Description \\
\hline Ear flicking & Calf rapidly moves one or both ears to the front and back independent of a head shake. \\
& Each time movement constitutes an ear flick. \\
Head shaking & Calf rapidly shakes head from one side to the other. Recorded as one behavior when the head moved \\
& Clowly or was in a resting position. \\
Head rubbing & Calf lifts hind leg to scratch top of head with foot or rubs head against sides of the pen. \\
Tail flicking & after the tail moved slowly or was in a resting position. \\
Foot stamping & Calf raises 1 foot and brings it down again firmly. \\
Head through bars & Calf puts head through the bars of the pen toward food and water buckets. This behavior was recorded \\
& at feeding time only (9 h following dehorning). \\
\hline
\end{tabular}

${ }^{1}$ Frequency of behavior events was recorded during each observational period.

Intakes of feed and water were recorded as kilograms consumed on each of the $3 \mathrm{~d}$ of the trial. Throughout the trial, calves were offered $3 \mathrm{~kg}$ of starter twice daily at approximately 0600 and $1600 \mathrm{~h}$. Feed and water were weighed again before the next morning feeding, and the amount consumed per 24 -h period was recorded at the morning feeding. This feeding regimen was ad libitum, because all calves had orts remaining each day.

\section{Statistical Analysis}

All data presented with heterogeneity of variance when assessed using Proc Univariate in SAS. Normality was achieved for activity data by use of a square root transformation, for algometer data by use of a quarter root transformation, and for feed and water intake data by use of a log transformation. Activity, algometer, feed, and water data were analyzed using a generalized linear model with Proc Mixed in SAS. Behavior (count) data were analyzed using a negative

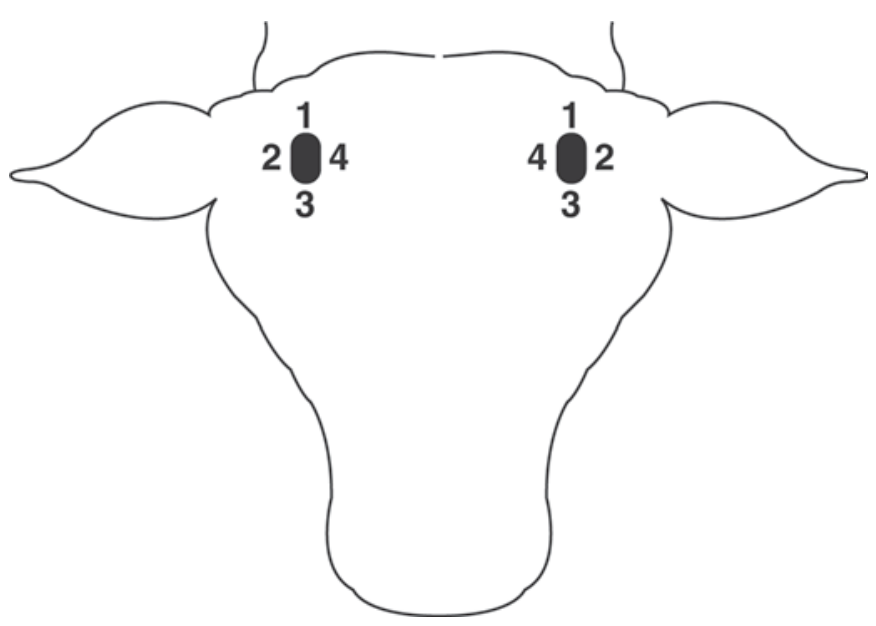

Figure 1. Locations around the horn bud measured by pressure algometry. Sites are labeled to indicate the order in which they were measured. binomial distribution in Proc Glimmix in SAS. For all measures, analyses of covariance were performed with observations taken at the corresponding period following the sham procedure as the covariate to determine the change from baseline.

For behavior and activity data, random effects of trial and of repeated measures on calf (nested within trial and treatment) were included in the model. Main effects included treatment, BW, age, covariate, days since weaning, and time of day. For algometer, feed intake, and water intake data, random effects included trial and calf (nested within trial and treatment). Main effects included treatment and day for feed and water data; and treatment, horn bud side, horn bud location, and first horn measured for algometer data. Interactions were tested and effects were eliminated using backward elimination if $P>0.1$. The autocorrelation structure with the lowest Akaike's information criterion (AIC) was used for the repeated measures. When significant effects $(P<0.05)$ were found, a multivariate $t$-test was used to adjust for multiple comparisons of treatment over each period. To compare over time within each treatment, Tukey's test was used.

\section{RESULTS}

There was an effect of treatment on ear flicking behavior (Figure 2). There were increases of $4.29 \pm 1.10$ and $1.31 \pm 0.66$ ear flicks/h on $\mathrm{d} 0$, and increases of $3.27 \pm 0.89$ and $0.55 \pm 0.50$ ear flicks/h on $\mathrm{d} 1$, for control and meloxicam calves, respectively $(F=10.65$, $\mathrm{df}=16, P=0.005)$. The total number of ear flicks $/ \mathrm{d}$ for control calves were 105,717 , and 539 on $\mathrm{d}-1,0$, and 1 , respectively, whereas the daily totals for the meloxicam calves were 219, 411, and 293. There was a tendency for increased ear flicking with increased calf age $(P=0.07)$.

A treatment by time interaction for changes in head shaking $(F=4.23$, df $=502, P=0.04)$ from baseline level behavior was identified (Figure 3 ). Increased head 


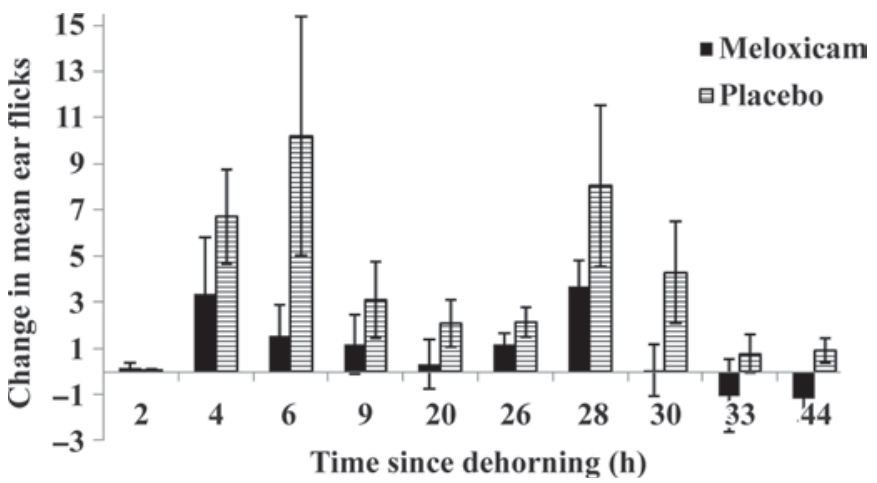

Figure 2. Change in mean $( \pm \mathrm{SE})$ frequency of ear flicking between each post-dehorning observational hour compared with the same hour after sham dehorning. Dehorning occurred at time 0. Meloxicam calves showed less ear flicking than controls $(P=0.005)$, with no treatmentby-time interaction.

shaking in control calves was greater $(P<0.05)$ than in meloxicam calves for $9 \mathrm{~h}$ following dehorning, after which there were no significant treatment effects. Control calves displayed $2.53 \pm 0.54$ more head shakes/h after dehorning, whereas meloxicam calves displayed an increase of $0.85 \pm 0.46$ head shakes/h. The total number of head shakes/d for the control calves were 137, 488 , and 240 on $\mathrm{d}-1,0$, and 1 , respectively, whereas the daily totals for the meloxicam calves were 230, 252, and 264 .

There were no significant effects of treatment on head rubbing or tail flicking. The total number of head rubs was 70,246 , and 260 for control calves and 97,236 , and 240 for meloxicam calves on $\mathrm{d}-1,0$, and 1 , respectively. Meloxicam calves displayed an average increase of 1.39 \pm 0.14 head rubs/h following dehorning, and control calves displayed an increase of $1.39 \pm 0.13 \mathrm{head} \mathrm{rubs} / \mathrm{h}$

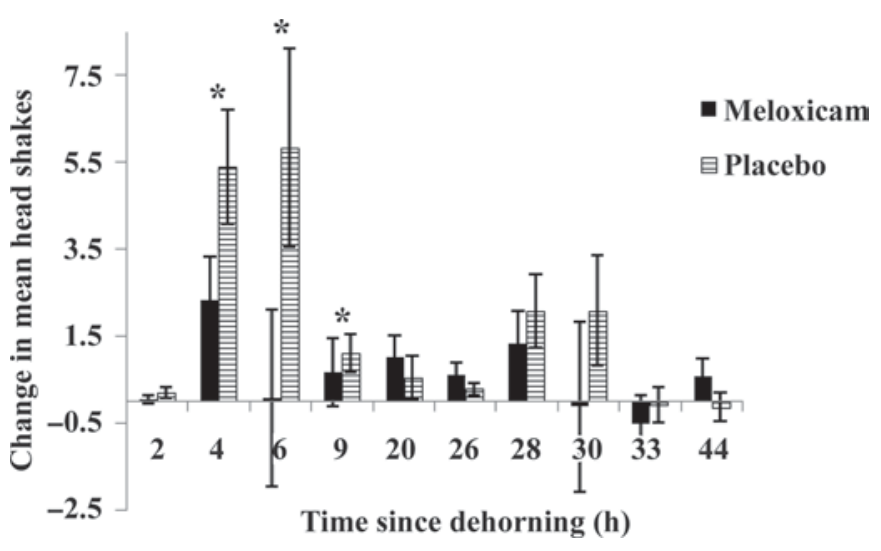

Figure 3. Change in mean $( \pm \mathrm{SE})$ frequency of head shaking between each post-dehorning observational hour compared with the same hour after sham dehorning. Dehorning occurred at time $0 .{ }^{*}$ Indicates period in which behavior of meloxicam calves differed from that of controls, $P \leq 0.05$.
$(F=0.37, \mathrm{df}=16, P=0.56)$. The total number of tail flicks was $1,106,3,544$, and 3,252 for control calves and $1,219,3,113$, and 2,949 for meloxicam calves on $\mathrm{d}$ $-1,0$, and 1 . Meloxicam calves displayed an increase of $17.96 \pm 1.41$ tail flicks/h following dehorning, and control calves displayed an increase of $19.13 \pm 1.54$ tail flicks $/ \mathrm{h}(F=0.03, \mathrm{df}=63, P=0.86)$. All calves showed increases in pain-related behaviors from baseline levels following dehorning $(P<0.05)$. There was a quadratic effect associated with time of day for each behavior $(P$ $<0.05)$. The frequency of behaviors was low early in the day, peaked in the afternoon, and then declined in the evening on all 3 trial days.

The accelerometer activity devices indicated that meloxicam calves were less active for the first $5 \mathrm{~h}$ following dehorning (activity $34.1 \pm 3.2$ and $30.6 \pm 2.6$ for control and meloxicam respectively; $P=0.02$ ). There were no further treatment by time interactions within this period and there were no other treatment differences.

Meloxicam calves displayed less sensitivity to pain in the pressure algometry test following dehorning compared with control calves $(\mathrm{MNT}=1.62 \pm 0.13 \mathrm{kgf}$ and $2.13 \pm 0.15 \mathrm{kgf}$ for control and meloxicam, respectively; $F=8.84, \mathrm{df}=55, P=0.004 ;$ Figure 4). Although all calves showed decreased tolerance to pressure following dehorning $(P=0.04)$, control calves were nearly twice as sensitive as meloxicam calves (decrease in MNT of 0.94 and 0.55 for control and meloxicam, respectively). There was an effect of the location measured on pain sensitivity $(P<0.0001)$, which was present on both days of the trial (Table 2). Locations 2 and 3 were the most sensitive compared with locations 1 and 4 . There was no effect of treatment on sensitivity by location. The effect of side (left or right horn) was not significant $(P=0.25)$.

The 4 calves that underwent 2 sham treatments showed no change in pressure sensitivity from the first to the second day $(P=0.3)$. Location effect was still evident, with location 2 being more sensitive than locations 1 and $4(P=0.004$ and 0.009 , respectively), and there was a trend for location 3 to be more sensitive than location $1(P=0.066)$.

Overall, feed intake did not differ between the treatments; however, there was a trend for meloxicam calves to consume more feed on $\mathrm{d} 1$ than on $\mathrm{d} 0(P=0.07)$. This increase in feed consumption did not occur with control calves $(2.9 \pm 0.17 \mathrm{~kg}$ on d 0 compared with $3.0 \pm 0.19 \mathrm{~kg}$ on $\mathrm{d} 1$ for controls; $2.7 \pm 0.18 \mathrm{~kg}$ on $\mathrm{d}$ 0 compared with $3.1 \pm 0.15 \mathrm{~kg}$ on $\mathrm{d} 1$ for meloxicam calves). There was a trend for meloxicam calves to put their heads through the bars in their pen toward feed and water more often than controls on d 0 (196 and 228 occurrences for control and meloxicam, respectively; $P$ 
Table 2. Mean $( \pm \mathrm{SE})$ mechanical nociceptive threshold ( $\mathrm{kg}$ of force causing withdrawal of head from algometer) at each location around the horn bud (see Figure 1)

\begin{tabular}{lll}
\hline Location & \multicolumn{1}{c}{ Sham } & Dehorning \\
\hline 1 & $2.68 \pm 0.10^{\mathrm{a}}$ & $2.21 \pm 0.34^{\mathrm{b}}$ \\
2 & $2.16 \pm 0.06$ & $1.61 \pm 0.12$ \\
3 & $2.56 \pm 0.12^{\mathrm{a}}$ & $1.90 \pm 0.17^{\mathrm{b}}$ \\
4 & $2.85 \pm 0.11^{\mathrm{a}}$ & $2.51 \pm 0.23^{\mathrm{c}}$ \\
\hline
\end{tabular}

${ }^{\mathrm{a}-\mathrm{c}}$ Locations with the same superscript do not differ $(P>0.05)$. Superscripts apply to day of trial only (sham or dehorning). There were no differences in treatment by location on either day of the trial.

$<0.1$ ). A treatment difference was not detected for this behavior on $\mathrm{d} 1$. There was a positive association between calf weight and intake, with heavier calves consuming more feed $(P<0.001)$. There was no difference in water intake between treatments.

\section{DISCUSSION}

This was the first study to examine the effect of meloxicam on calf behavior and pain sensitivity following dehorning. Meloxicam decreased cortisol, heart rate, and respiratory rate responses to dehorning in these calves (Heinrich et al., 2009) and reduced changes in heart rate and eye temperature (Stewart et al., 2009) after the surgery. In the current study, both meloxicam and control calves had increased ear flicking, head shaking, head rubbing, and tail flicking following dehorning. Increases in behavior previously associated with dehorning pain relative to the sham dehorning period were present to varying degrees during the 44-h study period, suggesting that calves may be uncomfortable during that time, despite analgesia. Control calves showed greater ear flicking and head shaking responses compared with meloxicam-treated calves, and these responses began approximately $2 \mathrm{~h}$ following dehorning. These responses corresponded with the duration of action of lidocaine and were consistent with the literature examining effects of ketoprofen on the same behaviors (McMeekan et al., 1999; Faulkner and Weary, 2000; Sylvester et al., 2004). The effect of ketoprofen on head shaking was not as robust as that on ear flicking, which was consistent with Faulkner and Weary (2000). In the current study, there was no treatment by time interaction for ear flicking, suggesting that meloxicam reduced ear flicking for the full $44 \mathrm{~h}$ of the trial. Our results support ear flicking as the most sensitive behavior for assessing dehorning pain. Head rubbing and tail flicking displayed by control calves did not differ compared with meloxicam calves, and this is in contrast to previous studies in which decreases in these behaviors associated with ketoprofen treatment were reported (McMeekan et al., 1999; Faulkner and
Weary, 2000). Discrepancy in results may be because of differences in NSAID effectiveness, methodology, or more complex multivariable statistical modeling in our study, which accounted for repeated measures within calves and a sham dehorning covariate period.

Another interesting aspect of these results is the apparent circadian pattern of pain-related behaviors, which appear to be lowest early in the day and peaking in mid-afternoon until evening feeding, after which they taper off again. This occurred on all $3 \mathrm{~d}$ of the trial so is unlikely to be attributable to pain sensitivity (because the calves were not dehorned on $\mathrm{d}-1$ ) or to our experimental methods (because calves were not handled on $\mathrm{d} 1$ ). There is a possible observer bias contributing to the apparent circadian pattern; however, frequency of behavior did not appear observer dependent when modeled. The patterns observed were based on one research farm, and a different pattern might be observed if the research were conducted at other farm locations.

Meloxicam-treated calves were less active than controls during the first $5 \mathrm{~h}$ following dehorning. Although there was no treatment by time interaction within the 5 $\mathrm{h}$, this difference appeared driven by behavior at time 0 (dehorning), as well as at h 4 and 5. Meloxicam calves may have been calmer during the dehorning procedure than the control calves and less restless during $\mathrm{h} 4$ and 5 when the lidocaine block would have worn off. Sedentary behavior during $\mathrm{h} 2$ and 3 post-dehorning may be an artifact of the methodology for collecting physiologic data (Heinrich et al., 2009), because calves were being routinely handled for blood sampling until 2 $\mathrm{h}$ post-dehorning; activity data and video observations corroborate that calves may have taken the departure of humans from the nursery as an opportunity for rest.

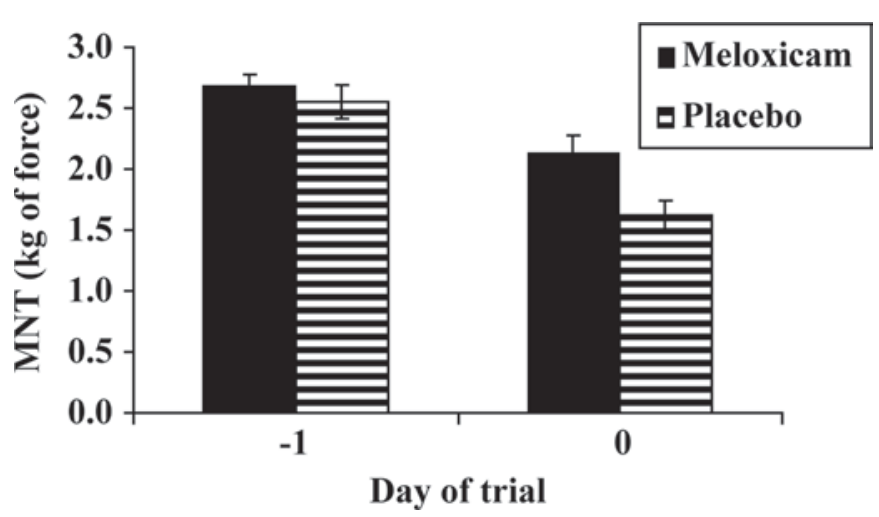

Figure 4. Mean $( \pm \mathrm{SE})$ mechanical nociceptive threshold (MNT, $\mathrm{kg}$ of force), as measured by pressure algometry following sham ( $\mathrm{d}-1)$ and actual dehorning ( $\mathrm{d} 0$ ). There was no difference in mean MNT between treatments on $\mathrm{d}-1(P>0.05)$. Change in MNT between $\mathrm{d}$ -1 and d 0 was greater in control calves $(P=0.004)$. 
The activity results are in contrast with other work. Milligan et al. (2004) and McMeekan et al. (1999) found no difference in the amount of lying behavior between calves that received lidocaine only and calves that received lidocaine plus ketoprofen. Methodology may be responsible for the differences because Milligan et al. (2004) disbudded calves with the smaller butane disbudding device at $2 \mathrm{~d}$ to 2 wk of age, and McMeekan and colleagues (1999) employed scoop dehorning on calves 3 to 4 mo old. In addition, the accelerometer used in this study was likely more sensitive than video analysis or direct behavioral observations. Alternatively, it is feasible that reduced pain experienced by meloxicam-treated calves facilitated resting behavior. This hypothesis is supported by increased rest when calves receive meloxicam as an adjunct therapy for diarrhea (Todd et al., 2010).

Calves had lower MNT following dehorning compared with sham dehorning, indicating that all calves were more sensitive to the mechanical stimulus following dehorning, regardless of treatment. However, the decrease in MNT was twice as great in calves that did not receive meloxicam, suggesting that the NSAID was effective at reducing pain associated with the procedure. Behavioral responses of the calves and physiological responses such as increased cortisol, heart rate, and respiratory rate following dehorning support the interpretation that this increased sensitivity to pressure was caused by pain (Heinrich et al., 2009). This was supported by results from the calves that were sham dehorned twice. Because the MNT of these calves did not decrease on the second day, it suggests that the decrease in MNT seen in the dehorned calves was caused by pain and was not a learned fear or avoidance response.

These differences in behavior and pain sensitivity were consistent with physiological data collected during this trial. Cortisol was lower in meloxicam-treated calves immediately following dehorning until $6 \mathrm{~h}$ postdehorning, and heart rate and respiratory rate were lower in meloxicam-treated calves for $24 \mathrm{~h}$ (Heinrich et al., 2009).

It is important to note that no calves were treated with meloxicam but not dehorned. Hence, some of the observed differences may be due to the drug alone rather than to pain. Several trials including both dehornedNSAID and nondehorned-NSAID treatment groups have been conducted, and the differences found in those studies in favor of NSAID treatment were related to the alleviation of cortisol response (McMeekan et al., 1998; Sutherland et al., 2002; Stafford et al., 2003) and painrelated behavior (McMeekan et al., 1999; Faulkner and Weary, 2000), not directly an effect of the drug itself.

In conclusion, it appears that pain following cautery dehorning with a local anesthetic may be present for up to $44 \mathrm{~h}$ following the procedure. Both groups of calves displayed significant elevations in ear flicking, head shaking, and pain sensitivity following dehorning. Calves treated with the NSAID meloxicam displayed less ear flicking and head shaking, less restlessness, and lower sensitivity to mechanical stimuli. Based on our results, it appears that meloxicam was effective at reducing pain following dehorning, and its ability to reduce pain for up to $44 \mathrm{~h}$ with a single injection makes it a potentially preferable choice over other NSAIDs.

\section{ACKNOWLEDGMENTS}

The authors thank Boehringer Ingelheim (Canada) Ltd., Boehringer Ingelheim Vetmedica Germany, Ontario Ministry of Agriculture Food and Rural Affairs, National Science and Engineering Research Council, and Canadian Foundation for Innovation for funding. We are grateful to Shelly James (Veterinary Teaching Hospital, Ontario Veterinary College, University of Guelph, Guelph, Ontario, Canada), Laura Wright and the staff at the Elora Dairy Research Centre (University of Guelph, Guelph, Ontario, Canada) for technical assistance, and William Sears and David Pearl (both of Department of Population Medicine, Ontario Veterinary College, University of Guelph, Guelph, Ontario, Canada) for statistical help. Melissa Sinclair (Department of Clinical Studies, Ontario Veterinary College, University of Guelph, Guelph, Ontario, Canada) kindly offered comments on an earlier draft of this work.

\section{REFERENCES}

Anil, S. S., L. Anil, and J. Deen. 2002. Challenges of pain assessment in domestic animals. J. Am. Vet. Med. Assoc. 220:313-319.

Curry, S. L., S. M. Cogar, and J. L. Cook. 2005. Non-steroidal antiinflammatory drugs: A review. J. Am. Anim. Hosp. Assoc. 41:298-309.

Duffield, T. F., A. Heinrich, S. T. Millman, A. DeHaan, S. James, and K. Lissemore. 2010. Reduction in pain response by combined use of local lidocaine anesthesia and systemic ketoprofen in dairy calves dehorned by heat cauterization. Can. Vet. J. 51:283-288.

Dyer, R. M., N. K. Neerchal, U. Tasch, Y. Wu, P. Dyer, and P. G. Rajkondawar. 2007. Objective determination of claw pain and its relationship to limb locomotion score in dairy cattle. J. Dairy Sci. 90:4592-4602.

European Agency for the Evaluation of Medicinal Products (EMEA). 2006. Scientific discussion, Metacam. 1-83. http://www.ema. europa.eu/vetdocs/PDFs/EPAR/metacam/032397en6.pdf Accessed Mar. 30, 2010.

Faulkner, P. M., and D. M. Weary. 2000. Reducing pain after dehorning in dairy calves. J. Dairy Sci. 83:2037-2041.

Gibson, T. J., C. B. Johnson, K. J. Stafford, S. L. Mitchinson, and D. J. Mellor. 2007. Validation of the acute electroencephalographic response of calves to noxious stimulus with scoop dehorning. N. Z. Vet. J. 55:152-157.

Graf, B., and M. Senn. 1999. Behavioral and physiological responses of calves to dehorning by heat cauterization with or without local anesthesia. Appl. Anim. Behav. Sci. 62:153-171.

Grøndahl-Nielsen, C., H. B. Simonsen, J. Damkjer Lund, and M. Hesselholt. 1999. Behavioral, endocrine and cardiac responses in 
young calves undergoing dehorning without and with the use of sedation and analgesia. Vet. J. 158:14-20.

Heinrich, A., T. F. Duffield, K. D. Lissemore, E. J. Squires, and S. T. Millman. 2009. The impact of meloxicam on post-surgical stress associated with cautery dehorning. J. Dairy Sci. 92:540-547.

Landoni, M. F., F. M. Cunningham, and P. Lees. 1995b. Determination of pharmacokinetics and pharmacodynamics of flunixin in calves by use of pharmacokinetic/pharmacodynamic modeling. Am. J. Vet. Res. 56:786-794.

Landoni, M. F., F. M. Cunningham, and P. Lees. 1995a. Pharmacokinetics and pharmacodynamics of ketoprofen in calves applying PK/PD modeling. J. Vet. Pharmacol. Ther. 18:315324.

Ley, S. J., A. E. Waterman, and A. Livingston. 1996. Measurement of mechanical thresholds, plasma cortisol and catecholamines in control and lame cattle: A preliminary study. Res. Vet. Sci. 61:172-173.

Liu, J., N. K. Neerchal, U. Tasch, R. W. Dyer, and P. G. Rajkondawar. 2009. Enhancing the prediction of accuracy of bovine lameness models through transformations of limb movement variables. J. Dairy Sci. 92:2539-2550.

McMeekan, C. M., K. J. Stafford, D. J. Mellor, R. A. Bruce, R. N. Ward, and N. G. Gregory. 1998. Effects of regional analgesia and/ or a non-steroidal anti-inflammatory analgesic on the acute cortisol response to dehorning in calves. Res. Vet. Sci. 64:147-150.

McMeekan, C. M., K. J. Stafford, D. J. Mellor, R. A. Bruce, R. N. Ward, and N. G. Gregory. 1999. Effects of local anesthetic and a non-steroidal anti-inflammatory analgesic on the behavioral responses of calves to dehorning. N. Z. Vet. J. 47:92-96.

Milligan, B. N., T. Duffield, and K. Lissemore. 2004. The utility of ketoprofen for alleviating pain following dehorning in young dairy calves. Can. Vet. J. 45:140-143.

Nolan, A., A. Livingston, R. Morris, and A. Waterman. 1987. Techniques for comparison of thermal and mechanical nociceptive stimuli in sheep. J. Pharmacol. Methods 17:39-49.
Papich, M. G. 2007. Saunders Handbook of Veterinary Drugs. 2nd ed. Sanders Elsevier, St. Louis, MO.

Petrie, N. J., D. J. Mellor, K. J. Stafford, R. A. Bruce, and R. N. Ward. 1996. Cortisol responses of calves to two methods of dehorning used with or without local anaesthetic. N. Z. Vet. J. 44:9-14.

Plumb, D. C. 2002. Veterinary Drug Handbook. 4th ed. Iowa State University Press, Ames.

Stafford, K. J., and D. J. Mellor. 2005. Dehorning and dehorning distress and its alleviation in calves. Vet. J. 169:337-349.

Stafford, K. J., D. J. Mellor, S. E. Todd, R. N. Ward, and C. M. McMeekan. 2003. The effect of different combinations of lignocaine, ketoprofen, xylazine and tolazoline on the acute cortisol response to dehorning in calves. N. Z. Vet. J. 51:219-226.

Stewart, M., K. J. Stafford, S. K. Dowling, A. L. Schaefer, and J. R. Webster. 2008. Eye temperature and heart rate variability of calves disbudded with or without local anesthetic. Physiol. Behav. 93:789-797.

Stewart, M., J. M. Stookey, K. J. Stafford, C. B. Tucker, A. R Rogers, S. K. Dowling, G. A. Verkerk, A. L. Schaeffer, and J. R. Webster. 2009. Effects of local anesthetic and a nonsteroidal antiinflammatory drug on pain responses of dairy calves to hotiron dehorning. J. Dairy Sci. 92:1512-1519.

Sutherland, M. A., D. J. Mellor, K. J. Stafford, N. G. Gregory, R. A. Bruce, and R. N. Ward. 2002. Cortisol responses to dehorning of calves given a 5-h local anaesthetic regimen plus phenylbutazone, ketoprofen or adrenocorticotropic hormone prior to dehorning. Res. Vet. Sci. 73:115-123.

Sylvester, S. P., K. J. Stafford, D. J. Mellor, R. A. Bruce, and R. N. Ward. 2004. Behavioral responses of calves to amputation dehorning with and without local anaesthesia. Aust. Vet. J. 82:697-700.

Todd, C. G., S. T. Millman, D. R. McKnight, T. F. Duffield, and K. E. Leslie. 2010. Non-steroidal anti-inflammatory drug therapy for neonatal calf diarrhea complex: Effects on calf performance. J. Anim. Sci. doi:10.2527/jas.2009-2340 